\title{
REVISITING CONTEMPORARY RESEARCH ON CREATIVITY IN LITHUANIA
}

\author{
Aurelija Ganusauskaité ${ }^{1}$, Jolita Vveinhardt ${ }^{2}$ \\ ${ }^{1}$ Vytautas Magnus University. Address: K. Donelaičio St. 58, 44248 Kaunas, Lithuania. Tel. + 370698 \\ 79362.Email: aurelija.ganusauskaite@vdu.lt. \\ ${ }^{2}$ Vytautas Magnus University. Address: K. Donelaičio St. 58, 44248 Kaunas, Lithuania. Tel. + 370698 \\ 06668.Email: jolita.vveinhardt@vdu.lt.
}

Received 1706 2020-06, Accepted 29062020

In this study, contemporary research on creativity was investigated by conducting the analysis of scientific articles in peer-reviewed journals published within the period from January 1996 to December 2018. The search was performed in the Lithuanian Academic Electronic Library (eLABa) entering search terms "kūrybingumas" (creativeness) and/or "kūrybiškumas" (creativity). The meta-analysis was conducted based on Magyari-Beck's $(1990,2010)$ taxonomy for the meta-analytical study on creativity, which classifies creativity research employing a matrix. The total of 109 articles were chosen for the analysis after applying the exclusion criteria. Freeman-Halton exact test was used to compare distributions of aspects or levels across disciplines. In addition to typological classification, word frequency analysis was performed in Psychology, Business Administration, Philosophy and Education disciplines and main context keywords and themes in each discipline were revealed. Seeking to identify possible topics in all articles with available full content in pdf $(\mathrm{N}=80)$, this dataset was analyzed employing qualitative analysis and processing it with NVivo10 qualitative data analysis software.

Keywords: creativity, creatology matrix, meta-analytic study, Lithuania.

JEL Codes: O31, M14.

\section{Introduction}

This study was conducted investigating creativity-related approaches based on the analysis of scientific research in the Lithuanian language, in this case scientific articles in peer-reviewed journals. Data were collected from the online Lithuanian Academic Electronic Library (eLABa). The meta-analysis was conducted based on Magyari-Beck's $(1990,2010)$ Creatology Matrix. The conceptual matrix was chosen because it is an appropriate tool enabling classification of possible trends in research on creativity and as it has also been used in other similar studies mentioned above. This taxonomy for the meta-analytical study on creativity classifies creativity research using the matrix that specifies three dimensions: the aspect on which the study focuses, the level at which it is investigated, and the approach used by the researcher. The aspects of creativity are further divided into traits, processes, and products; and the investigated levels, into individual, group, organization, and culture. Therefore, research approaches are divided as follows: research background and research analysis; in this case, we have four options: empirical qualitative, empirical quantitative, theoretical qualitative, and theoretical quantitative.

The idea and theoretical concept of the present study was inspired by several studies that have employed this typology: Wehner, Csikszentmihalyi, and Magyari-Beck's (1991), Kahl, da Fonseca, and Witte's (2009) and Tsai's (2014). Wehner et al. (1991) used the conceptual matrix for analyzing 100 dissertation abstracts that were published in 1986.

Copyright (C) 2020. Published by Vytautas Magnus University. This is an open access article distributed under the terms of the Creative Commons Attribution Non-Commercial 4.0 (CC BY-NC 4.0) license, which permits unrestricted use, distribution, and reproduction in any medium provided the original author and source are credited. The material cannot be used for commercial purposes. 
Kahl et al. (2009) investigated contemporary research on creativity by analyzing dissertation abstracts (sample, data were collected in Dissertation Abstracts Online, an information service provided by ProQuest Dissertations and Theses (PQDT, 2007). In this case, the keywords related to creativity were also used to collect the sample from the online database. Tsai (2014) used this matrix to examine doctoral dissertations related to the topic of creativity in Taiwan with the broader aim of understanding the researchers' attitudes and possible trends in the creativity research community of Taiwan.

This study aims to identify the trends of research on creativity, published in Lithuanian scientific literature. Analyzing the articles related to the topic of creativity in Lithuania, it is also sought to perceive researchers' approaches and highlight trends existing in research community investigating creativity in Lithuania. The study was implemented in three stages. In the first stage, based on the Magyari-Beck's $(1990,2010)$ classification matrix, research on creativity, conducted in Lithuania, was classified. In the second stage, applying statistical methods, distributions of aspects or levels across disciplines were compared. And finally, in the third stage, the qualitative analysis of articles with available full content in pdf was performed, seeking to investigate possible themes within this dataset. In order to discern the main themes in each discipline, the number of occurrences of context keywords was counted.

\section{Methods}

\subsection{Literature Identification}

Database. Data were collected from the online Lithuanian Academic Electronic Library (eLABa, https://www.elaba.lt/elaba-portal/), a national aggregated open access (OA) repository, in accordance with its legal regulation. eLABa consists of 6 science and study e-document collections: ETD (bachelor and master theses, doctoral dissertations and their summaries); Journals (periodic or one-time reviewed scientific and popular journals and other publications); Books (monographs, manuals, teaching books, their parts and others issues of science and studies); Proceedings (reports at scientific or methodological conferences, seminars and other scientific and educational events); Working Papers (research, development activities and project reports, and other research and study materials, prepared in e-form); Empirical Data (empirical data of research in humanitarian and social sciences), all created in Lithuania. All data retrieved were scientific articles in peer-reviewed journals published at eLABa within 1996-2018. Only this period was available in eLABa database.

Search Terms. Search terms in the current study were two Lithuanian words for "creativity" that can be translated as "kūrybingumas" and "kürybiškumas". As eLABa search engine does not allow to search for the root of the word, the scope was limited to two Lithuanian equivalents of the English word creativity: nouns "kürybingumas" and "kūrybiškumas". Other Lithuanian words related to the word creativity (e.g., derivatives "kūrybinis", "kūrybingas", "kūrybiškas", etc.) and the expression of their grammatical categories could be investigated in further research.

\subsection{Procedure}

Search method. Initially, retrieval with keywords ("kūrybingumas" and "kūrybiškumas") in eLABa search engine was performed. The inclusion criteria chosen were: a) the title and/or abstract of the article had to contain the search term: "kürybingumas" and/or "kürybiškumas"; b) the article had to be published in the peer-reviewed journal; c) it had to be written in the Lithuanian language. There were a few exclusion criteria: a) creativity was not the topic of the article (for example, even if the term is mentioned in the title and abstract, the main content includes nothing or few sentences about creativity); b) full abstract was not available or the abstract was insufficient.

Sampling. The retrievals obtained by the search term yielded amounts up to 203 scientific articles. The terms in Lithuanian "kūrybingumas" and "kūrybiškumas" returned $\mathrm{N}=62$ and $\mathrm{N}=$ 141, respectively. Therefore, the sampling procedure was reduced after non-mechanical, qualitative data analysis of scientific articles. Firstly, after listing all data, the same articles that appeared in the 
search by both terms were excluded: in "kürybingumas" and "kūrybiškumas" lists, there were $\mathrm{N}=73$ duplicate items in the entire sample. After exclusion of repetition, the total number of articles was $\mathrm{N}=130$. After screening 130 articles, 109 articles were chosen purposively by carefully assessing the title, abstracts and content (the full text) $(26$ - by title, abstracts; 83 - by full text). Excluded articles $(\mathrm{N}=20)$ were the ones that contained nothing or few sentences about creativity $(\mathrm{N}=4)$ and articles without full abstract or with insufficient one $(\mathrm{N}=16)$. Finally, after applying the exclusion criteria, 109 articles were chosen for analysis.

\section{Data Extraction}

a. The total list of articles comprised 203 articles.

b. After exclusion of repetition $(\mathrm{N}=73)$, the total number of articles was 130 .

c. Having screened 130 articles, 109 articles were chosen purposively by carefully assessing the title, abstracts and content (the full text) ( 26 - by title, abstracts; 83 - by full text).

d. Finally, after applying exclusion criteria, 109 articles were chosen for analysis.

Coding. After exclusion of duplicate articles in the entire sample and application of exclusion criteria, the sample of 109 articles was coded. Each article was coded making reference to the following: (a) author, (b) title, (c) date of publication, (d) discipline, (e) abstract, (f) typology, and (g) key words provided by the author(s). According to typology, each article was coded using more detailed categories of Kahl et al. (2009) (described below), based on Magyari-Beck's (1990, 2010) typology. The categories assigned as aspect were identified as follows: the trait was checked when human features were the focus; the process, if the focus was on the way humans produce a creative outcome; the product was chosen if creative output was the main issue, no matter whether attributes or production was meant. The categories assigned as level were identified as follows: the category of the individual was selected when the investigated social unit comprised not more than one person, even if the study analyzed certain groups of people; the category of the group was chosen when investigating small groups of people seeking a common aim; the category of the organization, for investigation and contrasting of more than one type of group; and the category of culture, for the analysis of a certain culture or cross-cultural comparisons (Kahl et al., 2009). Furthermore, each category of aspect and level was supplemented with "other" category, considering the articles with specific themes and content, such as creativity concept and construct analysis or other theoretical articles where all creativity aspects and levels were mentioned.

First, all coding was entered in Microsoft Excel and afterwards converted to SPSS for further data analysis.

Data Analysis. In addition to typological classification, all articles with available full content in pdf were analyzed employing qualitative analysis, seeking to identify and analyze possible themes in this dataset. The total number of articles with available full content in pdf was $\mathrm{N}=80$ (on Psychology, $\mathrm{N}=10$; on Business Administration, $\mathrm{N}=15$; on Philosophy, $\mathrm{N}=8$; on Education, $\mathrm{N}=32$; and on Miscellaneous matters, $\mathrm{N}=15$ ). Word frequency analysis was performed for Psychology, Business Administration, Philosophy and Education disciplines, except articles on Miscellaneous matters due to diversity of their content. Articles of each discipline were downloaded and processed with NVivo10 qualitative data analysis software, performing word counts, assessing the frequency of the meaning with which each word appeared in the article. In order to distinguish main themes in each discipline, the number of occurrences of context keywords was counted.

\section{Results}

Disciplines. A total of $\mathrm{N}=109$ articles were analyzed. Most articles were published after 2006. The disciplines received were divided into six main categories (percentages in parentheses): Psychology (14.7\%), Education (44\%), Business Administration (20.2\%), Philosophy (7.3\%), and Miscellaneous (13.8\%) (see Table 1). The category Miscellaneous represents disciplines sparsely contributing to the sample: Philology, Informatics, Arts, Social Sciences, Communication and Information, Public Administration and Politics, etc. It is worth noting that a separate study may cover several disciplines, as interdisciplinarity is currently particularly promoted. Often, the 
research presented in articles is based on the interdisciplinary approach, but in this meta-analysis only the main trend is mentioned; therefore, we chose to attribute the articles to the first discipline indicated in eLABa database.

Table 1. Frequency and percentage across categories of disciplines for the entire sample $(\mathrm{N}=109)$

\begin{tabular}{|l|c|c|}
\hline Disciplines & Frequency & Percentage (\%) \\
\hline Psychology & 16 & 14.7 \\
\hline Education & 48 & 44.0 \\
\hline Business administration & 22 & 20.2 \\
\hline Philosophy & 8 & 7.3 \\
\hline Miscellaneous & 15 & 13.8 \\
\hline Total & 109 & 100.0 \\
\hline
\end{tabular}

Table 2 displays frequencies and percentages for the entire sample $(\mathrm{N}=109)$ across aspect and level dimensions. The analysis based on Magyari-Beck's (1990) typology demonstrated that in terms of aspects, the most investigated topic was abilities $(55 \%)$; while the least investigated, the process $(7.3 \%)$. In terms of levels, researchers mostly emphasized the individual's creativity (59.6 $\%)$, less popular topics were organizational creativity $(16.5 \%)$ and culture $(15.6 \%)$. In the aspect of levels, the least studied topic was group creativity $(2.8 \%)$.

Table 2. Classification for the entire sample $(\mathrm{N}=109)$ across aspect and level dimensions

\begin{tabular}{|c|c|c|c|c|c|}
\hline & Traits & Processes & Products & Other & \\
\hline Individual & 51 & 1 & 0 & 13 & $59.6 \%$ \\
\hline Group & 1 & 0 & 0 & 2 & $2.8 \%$ \\
\hline Organization & 3 & 6 & 1 & 8 & $16.5 \%$ \\
\hline Culture & 5 & 1 & 0 & 11 & $15.6 \%$ \\
\hline Other & 0 & 0 & 0 & 6 & $5.5 \%$ \\
\hline & $55.0 \%$ & $7.3 \%$ & $.9 \%$ & $36.7 \%$ & $100.0 \%$ \\
\hline
\end{tabular}

Comparing samples of disciplines. Freeman-Halton exact test ${ }^{1}$ (Freeman and Halton, 1951), Mehta and Patel (2013, p. 145) was used to compare distributions of aspects or levels across disciplines. Pairwise comparisons of disciplines for each aspect or level were performed using usual normality based z-test for proportions (see Blalock, 1972, p. 228-229, for example) at the 0.05 significance level with Bonferroni correction (Dunn, 1958), which adjusts the observed significance level for the fact that multiple comparisons are made. Significant differences are indicated in the cross-tabulation table with APA-style formatting using subscript letters (see Tables 3 and 4). Statistical analysis was performed for disciplines of Psychology $\mathrm{N}=16$, Business Administration $\mathrm{N}=22$, Philosophy $\mathrm{N}=8$ and Education $\mathrm{N}=48$, except Miscellaneous $\mathrm{N}=15$ due to diversity of content. In total, $\mathrm{N}=94$ articles were analyzed.

\footnotetext{
${ }^{1}$ Which is modification of Fisher's exact test and sometimes is also called by the same name.
} 
Table 3. Distributions of aspects across disciplines $(\mathrm{N}=94)$

\begin{tabular}{|c|c|c|c|c|c|c|}
\hline & \multicolumn{4}{|c|}{ Disciplines } \\
\hline & & & Psychology & Education & $\begin{array}{c}\text { Business } \\
\text { Administration }\end{array}$ & Philosophy \\
\hline \multirow[t]{8}{*}{ Aspect } & \multirow[t]{2}{*}{ Ability } & Count & $14 \mathrm{a}$ & $41 \mathrm{a}$ & $4 \mathrm{~b}$ & $0 \mathrm{~b}$ \\
\hline & & $\begin{array}{c}\text { \% within } \\
\text { Disciplines }\end{array}$ & $87.5 \%$ & $85.4 \%$ & $18.2 \%$ & $0.0 \%$ \\
\hline & \multirow[t]{2}{*}{ Process } & Count & $0 \mathrm{a}, \mathrm{b}$ & $1 \mathrm{~b}$ & $5 a$ & $0 \mathrm{a}, \mathrm{b}$ \\
\hline & & $\begin{array}{r}\% \text { within } \\
\text { Disciplines }\end{array}$ & $0.0 \%$ & $2.1 \%$ & $22.7 \%$ & $0.0 \%$ \\
\hline & \multirow[t]{2}{*}{ Product } & Count & $0 \mathrm{a}$ & $0 \mathrm{a}$ & $1 \mathrm{a}$ & $0 \mathrm{a}$ \\
\hline & & $\begin{array}{r}\text { \% within } \\
\text { Disciplines }\end{array}$ & $0.0 \%$ & $0.0 \%$ & $4.5 \%$ & $0.0 \%$ \\
\hline & \multirow[t]{2}{*}{ Other } & Count & $2 \mathrm{a}$ & $6 \mathrm{a}$ & $12 \mathrm{~b}$ & $8 \mathrm{~b}$ \\
\hline & & $\begin{array}{r}\text { \% within } \\
\text { Disciplines }\end{array}$ & $12.5 \%$ & $12.5 \%$ & $54.5 \%$ & $100.0 \%$ \\
\hline \multirow{2}{*}{\multicolumn{2}{|c|}{ Total }} & Count & 16 & 48 & 22 & 8 \\
\hline & & $\begin{array}{r}\text { \% within } \\
\text { Disciplines }\end{array}$ & $100.0 \%$ & $100.0 \%$ & $100.0 \%$ & $100.0 \%$ \\
\hline
\end{tabular}

Notes. Each subscript letter denotes a subset of Disciplines categories whose column proportions do not differ significantly from each other at the 0.05 level.

Exact test shows that distributions of aspects across disciplines differ significantly, $\mathrm{p}<0.001$. Comparison of column proportions using z-test with Bonferroni adjustment highlights these significant differences, $\mathrm{p}<.05$ in all cases:

- the ability prevails in Psychology and Education, much less in Business Administration and Philosophy (in Philosophy the percentage is even zero, but there are only 8 cases classified as the Philosophy discipline);

- percentage of the process aspect is greater in Business Administration than in Education (there are only 6 cases with this aspect; therefore, this result should be treated cautiously);

- mixed and other aspects are more common in Philosophy and Business Administration than in Psychology and Education (in Philosophy these aspects are present even in 100\% of analyzed articles).

Table 4. Distributions of levels across disciplines $(\mathrm{N}=94)$

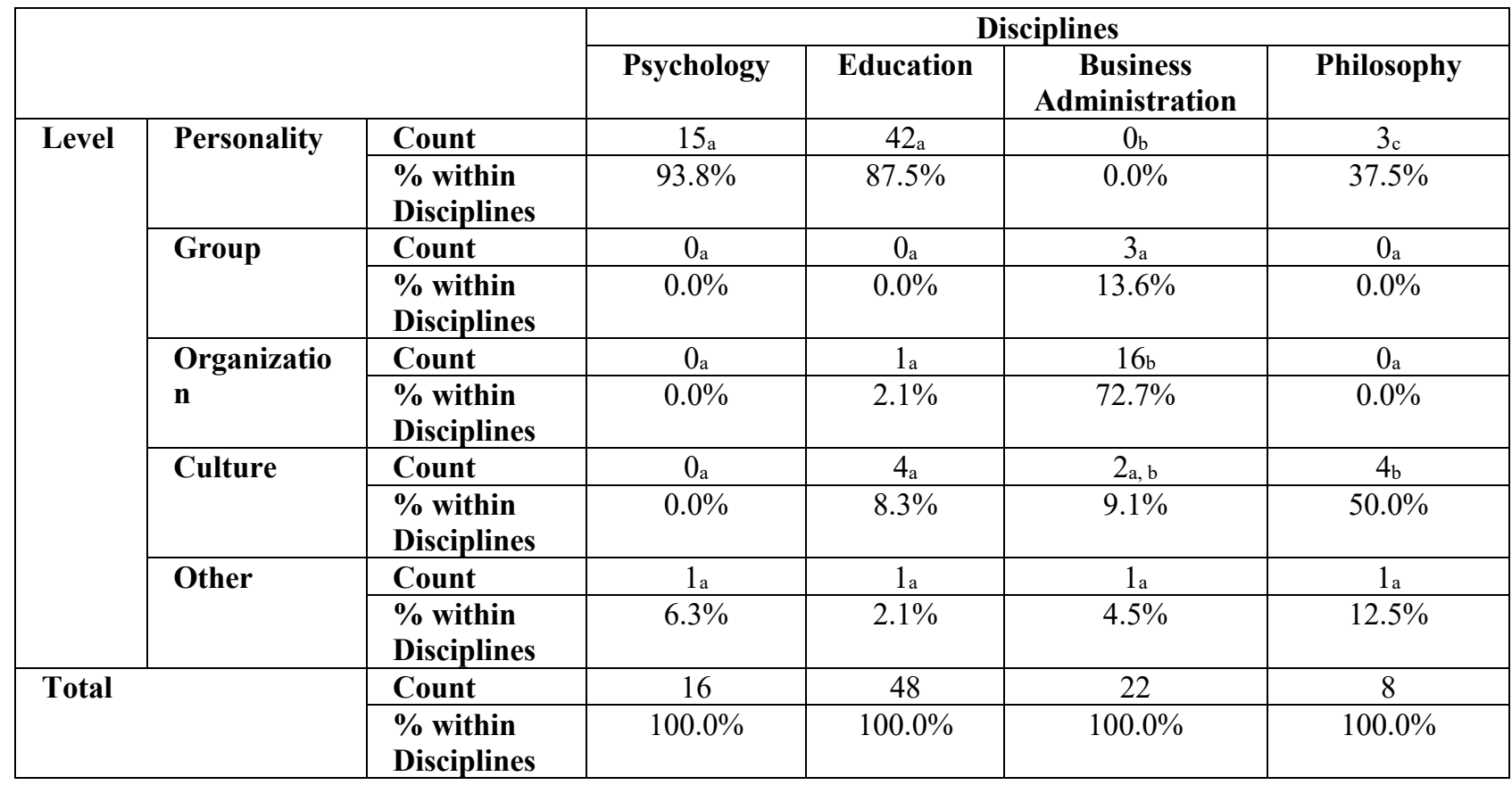


The exact test shows that distributions of levels across disciplines differ significantly, $\mathrm{p}<$ 0.001. Comparison of column proportions using z-test with Bonferroni adjustment highlights these significant differences, $\mathrm{p}<.05$ in all cases:

- the personality level is by far the main level in Psychology and Education, much less in Philosophy and especially in Business Administration where there are no such articles at all;

- the percentage of the personality level in Philosophy is also greater than in Business Administration, however, there are only 8 articles on Philosophy; therefore, this result should be considered only as preliminary;

- the organizational level is common in Business Administration, there is only one article at this level in all other disciplines; the cultural level is most common in Philosophy; much less, (close to zero), in Psychology and Education.

Word count in samples of disciplines. After performing word frequency analysis for Psychology, Business Administration, Philosophy and Education disciplines, main context keywords and themes in each discipline were revealed. Firstly, each word appearing in the article was assessed for frequency. Then, the full list of all words used in the articles was reviewed and contracted with the final list, with only noun and adjective lemmas ${ }^{2}$, summing up all grammatical categories (number, case). The final list is given bellow (Table 5).

Table 5. Lemma frequency in disciplines

\begin{tabular}{|c|c|c|c|c|}
\hline No. & $\begin{array}{l}\text { Psychology } \\
(\mathbf{N}=10)\end{array}$ & $\begin{array}{l}\text { Business Administration } \\
\qquad(\mathrm{N}=15)\end{array}$ & $\begin{array}{l}\text { Philosophy } \\
(\mathbf{N}=8)\end{array}$ & $\begin{array}{l}\text { Education } \\
(\mathbf{N}=32)\end{array}$ \\
\hline 1. & $\begin{array}{l}\text { Creativity (516) } \\
\text { (kūrybingumas) }\end{array}$ & Organization (661) & $\begin{array}{l}\text { Creative (kūrybinis) } \\
(272)\end{array}$ & Creativity (1564) \\
\hline 2. & Student (257) & Employee (585) & Creativity (227) & Studies (1553) \\
\hline 3. & Research (236) & Creative (kūrybinis) (433) & Creation (199) & Education (1439) \\
\hline 4. & Thinking (225) & Team (419) & Creativeness (198) & Research (1418) \\
\hline 5. & Personality (219) & Creativity (416) & Human (181) & Student (1359) \\
\hline 6. & Child (214) & Enterprise (412) & Knowing (153) & Activity (1312) \\
\hline 7. & Creative (kūrybiškas) (195) & Process (410) & Beauty (139) & Work (1276) \\
\hline 8. & Artistic (159) & Knowledge (394) & Art (120) & Learning (1116) \\
\hline 9. & The target group (153) & Work (355) & Term (116) & Teacher (1083) \\
\hline 10. & Group (152) & Idea (311) & Social (116) & Pupil (1046) \\
\hline 11. & Result (147) & Creativeness (296) & World (111) & Knowledge (900) \\
\hline 12. & Profile (143) & Method (292) & Philosophy (108) & Result (802) \\
\hline 13. & Creative (kūrybinis) (127) & Innovation (284) & Thing (100) & Program (778) \\
\hline 14. & Indicator (119) & Management (274) & Industry (95) & Process (767) \\
\hline 15. & Social (116) & Decision (251) & New (90) & School (743) \\
\hline 16. & Ability (111) & Creation (242) & Conception (82) & Ability (741) \\
\hline 17. & Trait (111) & New (240) & Activity (81) & Social (734) \\
\hline 18. & Originality (109) & Activity (234) & Culture (80) & Creative (kūrybinis) (696) \\
\hline 19. & Difference (109) & Human (214) & Idea (77) & Method (685) \\
\hline 20. & Estimate (102) & Problem (205) & Šliogeris (75) & Environment (685) \\
\hline 21. & Intellect (98) & Research (184) & Economics (75) & Teaching (684) \\
\hline 22. & Science (91) & Member (176) & Science (72) & Group (635) \\
\hline 23. & Psychology (88) & Internet (174) & Communication (69) & Evaluation (635) \\
\hline 24. & Human (87) & Factor $(170)$ & Society (68) & Human (630) \\
\hline 25. & Feature (86) & Creative (kūrybiškas) (144) & Plato (64) & Language (621) \\
\hline 26. & Education (85) & Executive (143) & Process (64) & Science $(602)$ \\
\hline 27. & Upbringing (84) & Ability (141) & Florida (63) & Child (599) \\
\hline 28. & Class (83) & Result (138) & Language (63) & New (555) \\
\hline
\end{tabular}

\footnotetext{
${ }^{2}$ In this article, the lemma is considered as a generalized conventional indicator of all forms of the inflectional lexical unit (Jakaitiene, 2010). For example, different grammatical forms of the word "namas" - tokens "namas", "namo", "namui", "namą", "namams", "namai", "namų" - are represented by a single lemma "namas".
} 
Aurelija Ganusauskaitè, Jolita Vveinhardt

Revisiting Contemporary Research on Creativity in Lithuania

\begin{tabular}{|l|l|l|l|l|}
\hline 29. & Learning (82) & Influence (130) & Domain (60) & Possibility (536) \\
\hline 30. & Age (77) & Thinking (129) & Attitude (57) & Domain (532) \\
\hline 31. & Parent (77) & Organizational (125) & Artistic (56) & Technology (525) \\
\hline 32. & Style (74) & Value (117) & Cultural (52) & Goal (525) \\
\hline 33. & Flexibility (71) & Perception (114) & Work (51) & Problem (514) \\
\hline 34. & Data (66) & Goal (109) & Communicative (49) & Respondent (512) \\
\hline 35. & Test (66) & Level (107) & Meaning (48) & Attitude (510) \\
\hline 36. & Birth (65) & Information (104) & Life (48) & Analysis (480) \\
\hline 37. & Pupil (63) & Creation (95) & Sociality (46) & Experience (473) \\
\hline 38. & Stress (62) & Condition (95) & Antique (45) & Competence (447) \\
\hline 39. & Time (57) & Characteristic (90) & Aristotle (44) & Quality (432) \\
\hline 40. & Task (55) & Openness (85) & $\begin{array}{l}\text { Product of creation } \\
(43)\end{array}$ & Information (4300 \\
& & & & \\
\hline
\end{tabular}

It can be assumed that in Psychology, Lithuanian researchers mostly focus on Personality (219) and creative thinking (225) styles (74). Basically, Profile (143), Ability (111), Trait (111), Characteristic (86) and Intellect (98) of the Personality are analyzed. According to thinking styles, Originality (109) and Flexibility (71), known as divergent thinking attributes, are mentioned most. The target group (153) of Research (236) are mainly Students (257), Children (214), Parents (77) or Pupils (63). Education (85), Upbringing (84) and Learning (82) are also common themes. Groups (152) are broadly analyzed too.

Research (184) on Business Administration is obviously focused on Organizations (661) / Enterprises (412) and its Teams (419) and Members (176), such as Employees (585) and Executives (143). Knowledge (394), Idea (311), Method (292), Innovation (284), Decision (251) and Problem (205) are broadly mentioned words.

Philosophy is dominated by current topicalities of the field, such as: Knowing (153), Beauty (139), Art (120), World (111), Conception (82), Culture (80), Society (68), Life (48), Meaning (48). Of course, the most mentioned subject is Human (181). Things (100) and Ideas (77) are also broadly analyzed. Main cited philosophers are Aristotle (44) Plato (64) and the Lithuanian philosopher Śliogeris (75).

In the field of Education, mostly mentioned subjects are Student (1359), Teacher (1083), Pupil (1046), Child (599) and Human (630) as a whole. Research (1418) is mostly concentrated on Studies (1553), Education (1439), Activity (1312), Work (1276), Learning (1116), Teaching (684), Evaluation (635), Analysis (480). Process (767), Method (685), Environment (685), Groups (635) are broadly analyzed as well.

\section{Conclusions}

The analysis of Lithuanian articles on Creativity topic revealed trends and gaps in research on creativity in Lithuania. The disciplines received were divided into six main categories, the majority belonged to Education and Business Administration; the rest, to Psychology, Philosophy and Miscellaneous. The analysis conducted based on Magyari-Beck's (1990) typology revealed that in the dimension of 'aspects', the most studied topic was abilities and in the dimension of 'levels', researchers placed most emphasis on the individual's creativity. Pairwise statistical comparisons of disciplines revealed that the ability prevailed in Psychology and Education, much less occurring in Business Administration and Philosophy. The process as the aspect is more common in Business Administration than in Education. According the level, personality is by far the main topic in Psychology and Education, while the organizational level is common in Business Administration; and cultural level, in Philosophy.

After performing the word frequency analysis for Psychology, Business Administration, Philosophy and Education disciplines, main context keywords and themes in each discipline were revealed. Summing up the content analysis of context keywords, it can be stated that each discipline concentrates on specific context keywords, although it can be noticed that Psychology and 
Education disciplines share common themes. Meanwhile, in Business Administration and Philosophy, current topicalities of the fields prevail.

The present study results provided profound insights to research on creativity in Lithuania, but there are a few issues worth noting. First, the present study focused only on scientific articles published in eLABa database and written in the Lithuanian language by narrowing search terms to "kürybingumas" and/or "kürybiškumas" (see in Search terms). The question remains what content and research trends are left behind in other studies on creativity, such as articles of Lithuanian authors published in the English language both in Lithuanian and other countries' scientific journals. How many publications were left behind by narrowing search terms?

Second, focusing on empirical or evidence-based research, empirical research articles should be analysed. In this sample, major articles were theoretical, such as literature reviews, theoretical discussions, and commentaries. Alternatively, all articles in other databases (S4) and articles in other peer-reviewed publications (S5) should be rejected, focusing only on those, which have been published in high-ranking scientific journals, concentrating only on high quality research. In this case, though, the data sample remains inappropriate, just few articles $(\mathrm{N}=10)$ are published in the Thomson Reuters Web of Science (S1).Therefore, it is recommended that continuing similar type research should be included articles of Lithuanian authors, presenting the results of empirical studies and published in English, for example, choosing only peer-reviewed journals in Web of Science (Clarivate Analytics) and/or Scopus databases for the analysis.

There are more options to provide a complete picture of the development of creativity research in Lithuania. For example, Long (2014) in his study claims that Mayer's (1999) synthesis presented a thorough overview of different ways of studying creativity; however, his classification of methodologies seemed to be grounded on a mixture of research methodologies and substantive contents, hence, resulting in some inconsistency. In this case, while the data sample was classified to four subcategories of the research approach (Empirical Quantitative, Empirical Qualitative, Theoretical Quantitative and Theoretical Qualitative), such questions as what specific methodologies and methods are distributed in creativity studies were not addressed. Thus, there remains room for further detailed research such as Long's (2014) meta-analytic study, focusing solely on the classification of methodologies.

\section{References}

Blalock, H. M. (1972). Social Statistics (2nd Ed.). McGraw-Hill Book Company.

Dunn, O. J. (1958). Estimation of the Means for Dependent Variables // Annals of Mathematical Statistics. Vol. 29. No. 4: 1095-1111.

Freeman, G. H., Halton, J. H. (1951). Note on an exact treatment of contingency, goodness of fit and other problems of significance // Biometrika. Vol. 38. No. 1-2: 141-149.

Kahl, C. H., da Fonseca, L. H., Witte, E. H. (2009). Revisiting Creativity Research: An Investigation of Contemporary Approaches // Creativity Research Journal. Vol. 21. No. 1: 1-5. doi:10.1080/10400410802633350

Long, H. (2014). An Empirical Review of Research Methodologies and Methods in Creativity Studies (2003-2012) // Creativity Research Journal. Vol. 26. No. 4: 427-438. doi:10.1080/10400419.2014.961781

Magyari-Beck, I. (1990). An introduction to the framework of creatology // Journal of Creative Behavior. Vol. 24. No. 3: 151-160. doi:10.1002/j.2162-6057.1990.tb00537.x

Magyari-Beck, I. (2010). Creatology: Past, Present and Future (An Overview). Avalaible at: http://creatology.hu/attach/Creatology\%20Past\%20Present\%20and\%20Future.pdf

Mehta, C. R., Patel, N. R. (2013). IBM SPSS Exact Tests. NY: IBM Corporation.

Tsai, K. C. (2014). Contemporary Creativity Research in Taiwan: A Critical Review // International Journal of Culture and History. Vol. 1. No. 2: 77-86. doi:10.5296/ijch.v1i2.6416

Wehner, L., Csikszentmihalyi, M., Magyari-Beck, I. (1991). Current approaches used in studying creativity: An exploratory investigation // Creativity Research Journal. Vol. 4. No. 3: 261-271. doi:10.1080/10400419109534398 